\title{
Indications of non-specific protective mechanisms in rainbow trout Oncorhynchus mykiss with diplostomosis
}

\author{
Johan Höglund ${ }^{1}$, Ann Thuvander ${ }^{2}$ \\ ${ }^{1}$ Department of Zoology, Uppsala University, Box 561, S-751 22, Uppsala, Sweden \\ ${ }^{2}$ Department of Pathology, Faculty of Veterinary Medicine, Swedish University of Agricultural Sciences, S-750 07, Uppsala, \\ Sweden
}

\begin{abstract}
To study effects on protective immunity in fish exposed to cercariae of the digenean Diplostomum spathaceum, rainbow trout (Oncorhynchus mykiss) were repeatedly infected with cercariae for a $12 \mathrm{wk}$ period at a water temperature of $15^{\circ} \mathrm{C}$. Intensity of infection, expressed as the relative density of metacercariae per fish, increased during the first $8 \mathrm{wk}$ and then reached a plateau in experimentally infected fish. However, the recovery of the parasite, i.e. the percentage of the total amount of cercariae that managed to establish themselves as metacercariae in the lens, decreased throughout the experimental period. Compared with control fish, the infected fish showed a marked increase in the proportions of neutrophils and monocytes in the peripheral blood and the level of total immunoglobulins was significantly higher. Specific antibody levels to antigens from 3 developmental stages of the parasites were determined in an ELISA. A specific antibody response in the infected fish was, however, not recorded. The continuous decrease in recovery of the parasite in this study indicate that repeated exposure to $D$. spathaceum induced some degree of protective immunity in the fish. As specific antibody production was not recorded in the infected fish, this protection is more likely to be related to cell mediated immunity or to non-specific mechanisms of protection than to a humoral antibody response.
\end{abstract}

\section{INTRODUCTION}

Diplostomosis is a parasitic disease of fish that in the chronic stage can result in blindness of the host. It is caused by metacercariae of the digenean Diplostomum spathaceum, which establish themselves in the eye lens of fish, which is an immunologically privileged site (Shariff et al. 1980). In this respect, D. spathaceum differs from many of the endoparasitic helminths, which evoke an antibody response in infected fish (Molnar \& Berzi 1965, Harris 1970, 1972, Harris \& Cottrell 1976, Cottrell 1977, McArthur 1978, Wood \& Matthews 1987, Szalai et al. 1988). However, recent studies of fish injected intraperitoneally (i.p.) with antigen preparations from $D$. spathaceum or with whole parasites have clearly shown that $D$. spathaceum can evoke a specific antibody response in the fish (Bortz et al. 1984, Whyte et al. 1987). Further, protective immunity to the parasite has been demonstrated in fish injected with dead parasites (Speed \& Pauley 1986, Stables \& Chappell 1986a).
Although injection of parasites obviously evokes both an antibody response and protective immunity in fish, there is a need for a long-term study on the development of protection in fish exposed to Diplostomum spathaceum by the natural route. The ability of migrating diplostomulae to induce a non-specific cellular response in fish infected with $D$. spathaceum has been reported from histological studies (Erasmus 1959, Ratanarat-Brockelmann 1974). Further, Bortz et al. $(1984,1988)$ detected antibodies to Diplostomum spp. in infected wild fish. In contrast, Stables \& Chappell (1986a) were unable to show a humoral antibody response in rainbow trout experimentally exposed to cercariae of $D$. spathaceum. However, the infection rate differed between experiments performed at the same temperature during summer and winter and was interpreted as an induction of protective mechanisms in their study.

The present experiment was designed to study if fish repeatedly exposed to cercariae develop protective mechanisms and if so, whether the protection is related to specific immunity. For this purpose rainbow trout 
were kept in water at $15^{\circ} \mathrm{C}$ and were repeatedly exposed to Diplostomum spathaceum during a $12 \mathrm{wk}$ period. The infection rate of the parasite as well as haematological and immunological parameters in the fish were followed.

\section{MATERIALS AND METHODS}

Fish. One-year old rainbow trout $(45 \pm 2$ g) from Färnäs hatchery (Sweden) were kept in an artificial light regime simulating outdoor conditions at a temperature of $15 \pm 1^{\circ} \mathrm{C}$ in $400 \mathrm{l}$ tanks. The water was recirculated through a sandfilter and continuously aerated. The fish were fed daily with onmmercial trout nellets (EWOS) ad libitum.

Production of antigen. Infective larvae (cercariae) and post-penetration larvae (diplostomulae) were produced according to Whyte et al. (1988). Parasite eggs obtained from the faeces of experimentally infected herring gulls (Largus argentatus) were incubated for 9 to $11 \mathrm{~d}$ at $28^{\circ} \mathrm{C}$. Hatched miracidiae were collected and snails of a laboratory strain of Lymnea palustris were exposed to infection with 4 miracidiae for $6 \mathrm{~h}$ at room temperature. Snails were tagged with nail polish and housed in $100 \mathrm{l}$ glass tanks in a constant temperature room at $18^{\circ} \mathrm{C}$ under $12 \mathrm{~h}$ light: $12 \mathrm{~h}$ dark regime. They were fed ad libitum on fresh lettuce supplemented by commercial fish food (Tetra Werke, F. R. Germany). The water in the tanks was continuously recirculated through a bottomfilter (Eheim) and aerated. Within 7 to $10 \mathrm{wk}$ post-exposure to miracidia, shedding of cercariae commenced and cercariae were collected by isolating infected snails in $50 \mathrm{ml}$ beakers for $12 \mathrm{~h}$ under warm, light conditions. The cercariae suspensions from the individual snails were pooled and the density of cercariae was estimated in six $0.2 \mathrm{ml}$ aliquots stained with Lugols iodine.

The post-penetration larvae, the diplostomulae, were collected after penetration of isolated pieces of rainbow trout skin, using the technique described by Whyte et al. (1988). The upper compartments of the skin-penetration tubes were filled with cercarial suspension while the lower compartments were filled with RPMI cell culture medium (Gibco). Tubes were incubated overnight in bright light conditions at room temperature

Metacercariae were obtained from the lens of rainbow trout at least 6 wk post-infection with cercariae.

Infection of fish with cercariae. Two hours prior to infection, the fish were placed in an infection box with individual compartments, each inhabited by 1 fish and filled with 1.21 of aerated water. Each fish was exposed for $15 \mathrm{~min}$ to a weekly dose of ca 200 cercariae. Five groups of fish were exposed for $1,3,5,8$ or 12 wk, respectively Corresponding groups of control fish were sham exposed under identical conditions. The experiment was performed between June and August.

Sampling. Each group was sampled at 1,3,5,8, and $12 \mathrm{wk}$, respectively; 15 to 17 fish were anaesthetized with MS 222 (Sandoz) and blood samples were collected from the caudal vein in heparinized vacutainer tubes. The blood was then centrifuged at $300 \times g$ for 10 min. Plasma was stored at $-20^{\circ} \mathrm{C}$ before screening in the ELISAs. The total length and weight of each fish was measured. In addition, the eyes were dissected and the number of metacercariae was determined using a stereo-microscope ( $\times 50)$.

Differential counts of blood leukocytes. Blood smears were fixed in methanol and stained with Hemacolour (Merck), and differential counts of 100 to 200 leucocytes were made.

Preparation of positive and negative control plasma samples. To obtain positive plasma, rainbow trout were injected i.p. with whole frozen parasites. Each fish received ca 200 cercariae, 300 diplostomulae, or 50 metacercariae. Two weeks later, a booster dose was given and after another $2 \mathrm{wk}$, fish were bled. The plasma samples obtained in this manner served as positive control samples in the ELISA. Negative control samples were obtained from non-infected rainbow trout.

Antigen preparation. Antigens from 3 developmental stages (cercariae, diplostomulae and metacercariae) were prepared by alternately freezing and thawing as described by Ingram \& Al-Yaman (1988). Briefly, the parasites were diluted to ca 100 organisms $\mathrm{ml}^{-1}$ in $0.05 \mathrm{M}$

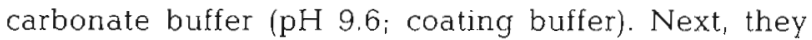
were alternately frozen $\left(-20^{\circ} \mathrm{C}\right)$ and thawed 5 times. The antigen preparations were then centrifuged for $10 \mathrm{~min}$ at $200 \times g$. The resulting supernatants were then used as coating antigens in the ELISA measuring antibodies to Diplostonum spathaceum.

ELISA-antibodies to Diplostonum spathaceum. A modification of the indirect ELISA system described by Whyte et al. (1987) was used to determine plasma antibody levels to Diplostonum spathaceum. Microtitre plates (Nunc II Immunoplate, Nunc, Denmark) were coated at room temperature for $24 \mathrm{~h}$ with $200 \mu \mathrm{l}_{\text {well }}{ }^{-1}$ of one of the 3 different antigen preparations diluted $1: 20$ (cercariae) or 1:50 (diplostomulae and metacercariae) in coating buffer. After removal of the antigen solution, the plates were blocked with 200 ul well ${ }^{-1}$ of $2 \%$ milk powder in phosphate buffered saline (PBS) for $30 \mathrm{~min}$. After this, plates were washed 3 times with $0.9 \% \mathrm{NaCl}$ with $0.5 \%$ Tween 20 , and $100 \mu$ of fish plasma, diluted $1: 100$ in PBS with $0.5 \%$ Tween 20 (PBS-Tween), was added to each well Duplicate wells were used for each sample. Following overnight incubation at $4^{\circ} \mathrm{C}$ the plates were again washed as above and then incubated with $100 \mu$ well $^{-1}$ of a mouse 
monoclonal antibody (clone 4C10 in ascites fluid) to rainbow trout IgM (Thuvander et al. unpubl.) diluted $1: 10000$. The plates were incubated for $1.5 \mathrm{~h}$ at $37^{\circ} \mathrm{C}$. After washing, plates were incubated with $100 \mu \mathrm{l}$ well $^{-1}$ of horseradish peroxidase conjugated rabbit anti-mouse antibodies (Dakopatt, Denmark) diluted 1:1500 in PBS-Tween. Finally, after washing, $200 \mu$ well ${ }^{-1}$ of the substrate tetramethylbenzidine (TMB, $\mathrm{KEBO}$, Stockholm) at a concentration of $1 \mathrm{mg} \mathrm{ml}^{-1}$ in $0.1 \mathrm{M}$ acetate buffer, $\mathrm{pH} 6.0$, containing $2 \mu \mathrm{l} 3 \% \mathrm{H}_{2} \mathrm{O}_{2}$ $\mathrm{ml}^{-1}$ was added. The reaction was stopped after $10 \mathrm{~min}$ with $50 \mu$ well $^{-1} 2 \mathrm{M} \mathrm{H}_{2} \mathrm{SO}_{4}$, and the optical density (OD) at $450 \mathrm{~nm}$ determined. Results are expressed as the mean OD values for duplicate wells.

ELISA-total immunoglobulin. Microtitre plates were coated for $24 \mathrm{~h}$ at room temperature with $200 \mathrm{\mu l} \mathrm{well}^{-1}$ of rabbit anti-trout IgM sera diluted 1:1000 in coating buffer. Subsequently the plates were washed 3 times. After this, fish plasma serially diluted in PBS-Tween was added and the plates were incubated overnight at $4{ }^{\circ} \mathrm{C}$. Following this step the procedure described above, for detection of bound fish antibodies, was employed. Results are expressed as $O D$ value for plasma diluted 1:1600.

Statistical analysis and definitions. The numbers of parasites were compared with Kruskall-Wallis test and Mann-Whitney U-test. Haematological and immunological parameters were tested with Student's t-test and analysis of variance (ANOVA). All of the statistical tests were 2 -tailed and considered significant at the 0.05 level

Relative density of metacercariae refers to the number of larvae per fish at autopsy. Recovery refers to the percentage of the total amount of cercariae that managed to establish themselves as metacercariae in the lens.

\section{RESULTS}

\section{Experimental infections}

As can be seen in Fig. 1a, the relative density of metacercariae in the lens increased gradually in the exposed fish for the first $8 \mathrm{wk}$ of exposure (Kruskall Wallis test, $\mathrm{DF}=4, \mathrm{H}=56.87, \mathrm{p}<0.001$ ). The mean number of metacercariae per fish was $149 \pm 48$. After 8 $w k$ of exposure the relative density of metacercariae reached a plateau (Mann Whitney U-test, $\mathrm{N}=33, \mathrm{Z}=$ $0.11, \mathrm{NS})$.

The percentage of the total amount of cercariae that managed to establish themselves as metacercariae in the lens, i.e. the recovery, decreased continuously throughout the experiment (Fig. 1b). The lens was the only site in the eye found to be infected. All of the fish in the control groups remained uninfected throughout the experiment.

\section{Haematology}

Results from the differential leucocyte counts are shown in Fig. 2. Four clearly distinct cell-populations, namely lymphocytes, thrombocytes, neutrophilic granulocytes (neutrophils) and monocytes were identified in the blood smears (Thuvander et al. 1987).

A general increase in the proportion of neutrophils was recorded for both groups of fish during the experiment. The proportions of neutrophils were, however, significantly higher in the experimentally infected fish than in the controls (2-way ANOVA: weeks of exposure, $F=18.19, p<0.0001$; treatment, $F=11.43, p<$ 0.0001 ; interaction between weeks of exposure and treatment, $\mathrm{F}=3.54, \mathrm{p}<0.018$ ).

The proportion of monocytes increased in the infected fish but not in the control fish throughout the experimental period. As for the neutrophils, this cell population was also higher in the infected fish than in the controls (2-way ANOVA: weeks of exposure, $F=$ $10.74, \mathrm{p}<0.0015$; treatment $, F=5.39, \mathrm{p}<0.0018$; interaction between weeks of exposure and treatment, $F=1.94, p<0.12$ )

The proportion of lymphocytes decreased significantly in both groups of fish throughout the experimental period. The relative lymphocyte counts were, how-
Fig. 1. Infection rate of Diplostomum spathaceum in rainbow trout exposed to a weekly dose of 200 cercariae as described in detail in 'Material and methods'; shown as (a) the relative density of metacercariae, and (b) mean recovery, i.e. the percentage of the total amount of cercariae that managed to establish themselves as metacercariae in the lens of fish. Results are expressed as mean \pm SD for 15 to 17 fish a

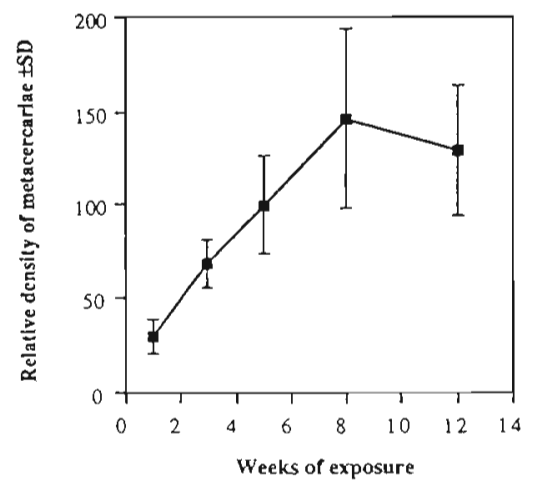

b

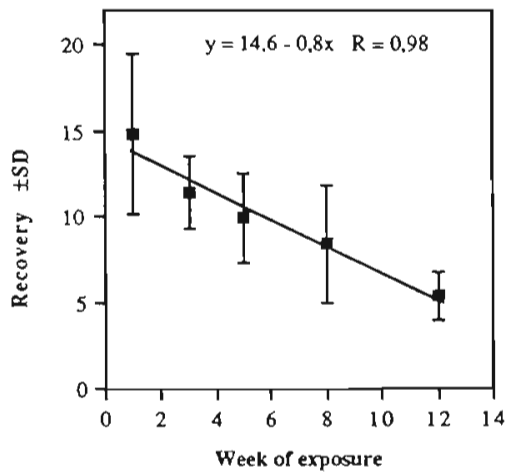


a

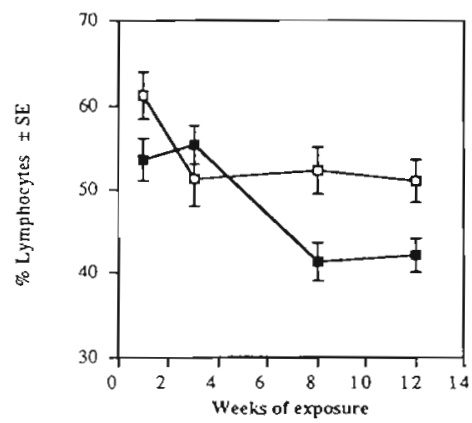

$\mathrm{c}$

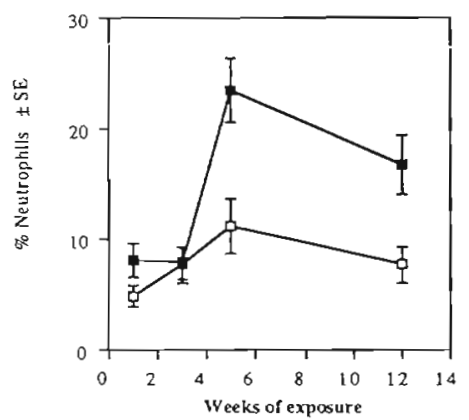

b

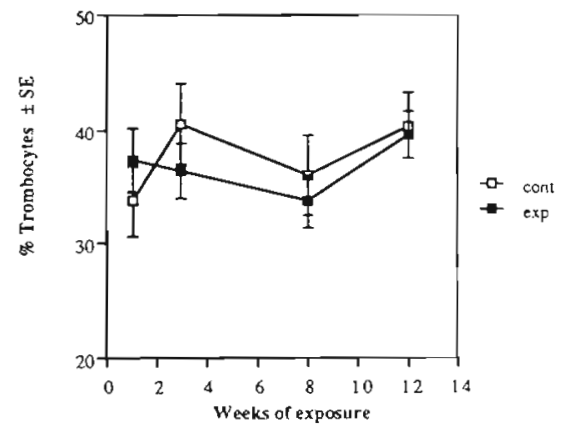

d

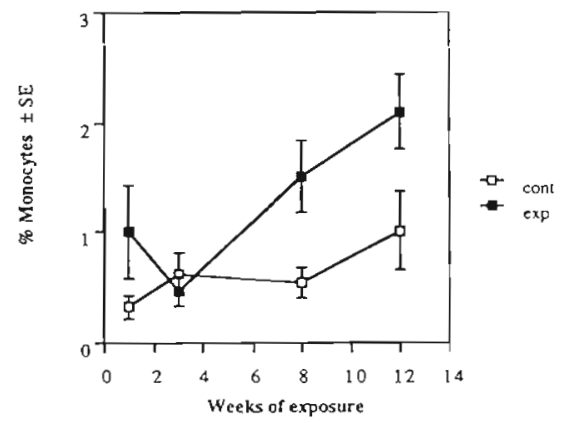

Fig. 2. Differential leucocyte counts in control rainbow trout and in fish experimentally infected with live Diplostomum spathaceum cercariae; (a) lymphocytes, (b) thrombocytes, (c) neutrophils, (d) monocytes. Results are expressed as mean $\pm \mathrm{SE}$ for 10 to 15 fish ever, significantly lower in the infected fish as compared to the controls (2-way ANOVA: weeks of exposure, $F=8.55, p<0.0001$; treatment, $F=10.50, p<$ 0.0016 ; interaction between weeks of exposure and treatment, $F=3.40, \mathrm{p}<0.021$ ).

The proportions of thrombocytes remained unaltered throughout the experiment in both groups of fish (ANOVA: $F=0.88, p<0.52$ ).

\section{Total Ig levels}

OD values for fish in the ELISA measuring total Ig levels are shown in Fig. 3a. Although the total Ig levels were significantly higher in infected fish than in controls, a general increase in OD values was also observed during the experimental period, i.e. total Ig levels increased in both infected and control fish over the summer (2-way ANOVA: weeks of exposure, $F=8.36, p<0.0001$; treatment, $F=5.84, p<0.017$ i interaction between weeks of exposure and treatment, $F=3.20, p<0.015$ ).

\section{Specific antibody levels}

As can be seen in Fig. 3b to d, the ELISA measuring specific antibodies to cercariae, diplostomulae and metacercariae revealed no differences in $O D$ values between infected and control fish. Instead, a general increase in OD values that correlated with the observed increase in total antibodies, was observed in both groups of fish throughout the experiment (2-way ANOVA, cercariae: weeks of exposure, $F=3.96, p<$ 0.005 ; treatment, $F=1.31, p<0.25$; interaction between weeks of exposure and treatment, $F=0.135$, $p<0.97$; diplostomulae: weeks of exposure, $F=6.30$, $\mathrm{p}<0.0001$; treatment, $\mathrm{F}=0.085, \mathrm{p}<0.77$ i interaction between weeks of exposure and treatment, $F=0.73$; $\mathrm{p}<0.58$; metacercariae: weeks of exposure, $\mathrm{F}=3.83$, $p<0.006$; treatment, $F=0.33 ; p<0.5$; interaction between weeks of exposure and treatment, $F=1.18$, $p<0.32$ )

The results of the estimations of antibodies in plasma from fish injected i.p. with parasitic antigens are shown in Fig. 4. OD values were significantly higher for fish immunized with cercariae (Students' $t$-test, $t=3.69$, $p<0.0027$ ), diplostomulae (Students' t-test, $t=3.26$, $p<0.0099$ ) or metacercariae (Students' $t$-test, $t=3.37$, $\mathrm{p}<0.0055$ ) than for control fish.

\section{DISCUSSION}

In this study, the relative density of metacercariae in fish increased up to Week 8 and then reached a plateau. As the timing of the plateau did not coincide with 
Fig. 3. Humoral antibody levels expressed as $\mathrm{OD}_{450}$-values to antigens from Diplostomum spathaceum in experimentally infected and control rainbow trout - as described in detail in 'Material and methods'. Results are expressed as mean $\pm S E$ for 8 to 16 fish. (a) Total immunoglobulin levels; (b) antibodies to cercariae; (c) antibodies to diplostomulae; (d) antibodies to metacercariae
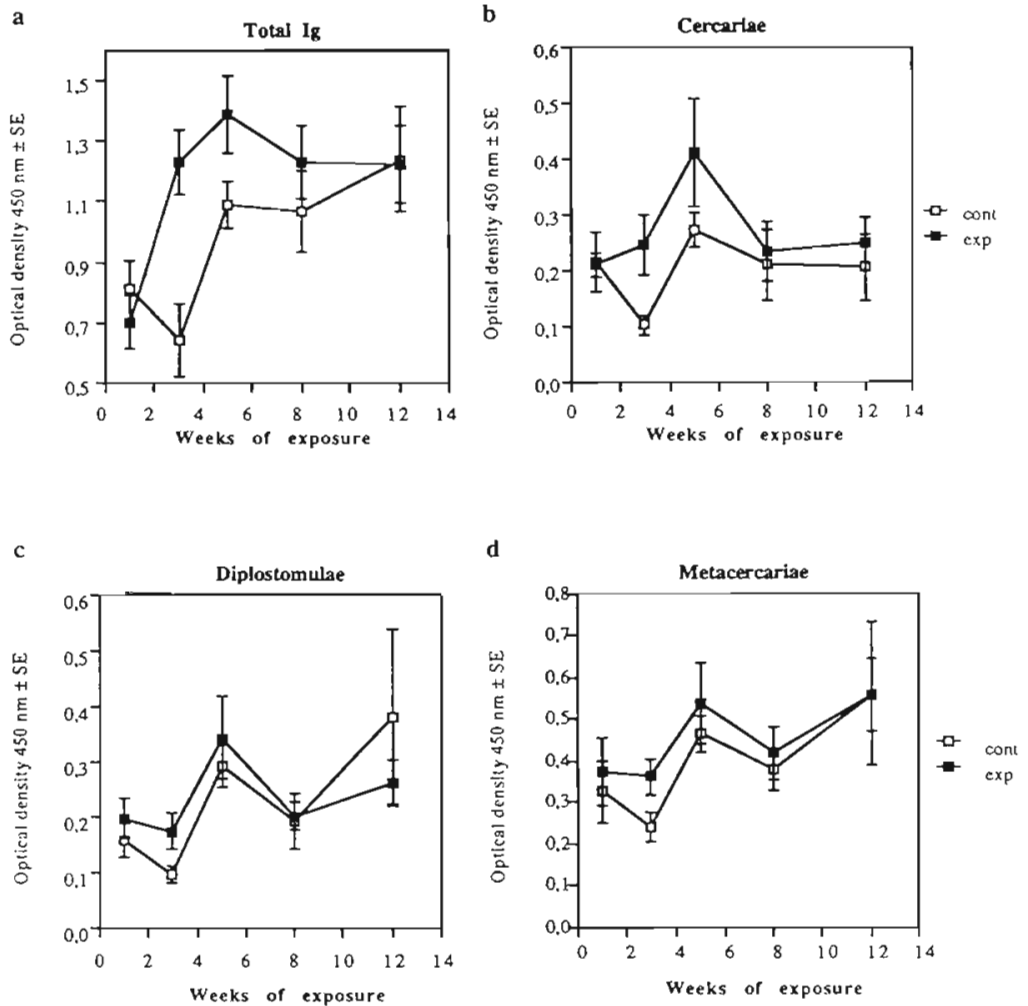

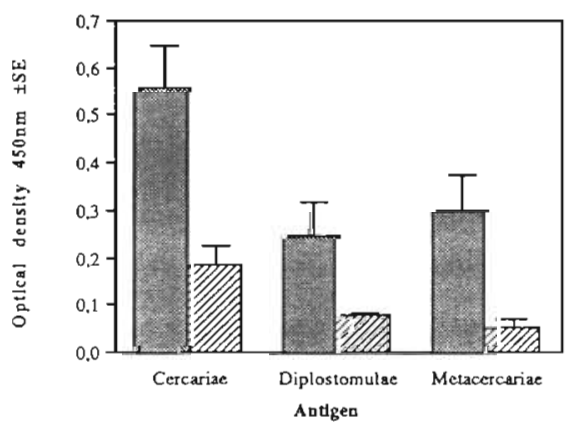

Fig. 4. Humoral antibody levels expressed as $\mathrm{OD}_{450^{-v} \text {-values to }}$ antigens from Diplostomum spathaceum in rainbow trout injected i.p. with the different developmental stages of the parasite and in control fish - as described in detail in 'Material and methods'. Results are expressed as mean \pm SE for 4 to 8 fish

observed changes in haematological or immunological parameters, the saturation was probably due to space limitations in the lens. More importantly, the recovery of the parasite decreased continuously throughout the 12 wk experimental period. Since we used laboratorymaintained cercariae bred under identical conditions throughout the experiment, it is not likely that the decrease in infection rate was due to a decreased ability of the cercariae to infect the fish. Further, the life span of the metacercariae of Diplostonum spathaceum is several years, and losses due to natural mortalities of metacercariae can thus be neglected (Stables \& Chappell 1986b). A possible explanation for the decreased recovery of the parasite would be related to structural changes in the fish skin or gill epithelium associated with the growth of the fish during the experiment. A more probable explanation is, however, that the decreased recovery of the parasite was due to the induction of mechanisms in the fish protective against the migrating diplostomula. The infection pattern observed in this experiment suggests that protective mechanisms are induced in fish following repeated exposure of the fish to live cercariae of $D$. spathaceum. This finding agrees with several reports on induction of protective mechanisms in fish exposed to endoparasitic helminths (Kennedy \& Walker 1969, Orr et al. 1969, McVicar \& Fletcher 1970, Wood \& Matthews 1987).

We were unable to detect a specific humoral antibody response in rainbow trout repeatedly infected with cercariae of Diplostonum spathaceum by the natural route. This result is similar to observations reported by Stables \& Chappell (1986a) but contrasts with studies of wild fish (Bortz et al. 1984, 1988) in which antibodies to $D$. spathaceum were detected. However, in agreement with previous reports (Bortz et al. 1984, Whyte et al. 1987), a specific antibody response was observed in the present study in fish following i.p. immunization with 3 different developmental stages of the parasite. The absence of a specific antibody response to $D$. spathaceum in this experiment 
is therefore, not likely to be due to the use of an inappropriate immunological assay, although the present method might not be sensitive enough to reveal a weak antibody response.

Even though no specific antibody response to Diplostonum spathaceum was observed among the experimentally infected fish in this study, the total immunoglobulin levels were significantly higher in the experimentally infected fish when compared with controls. This finding might be the result of a weak antibody response to several antigens derived from the infecting parasite. Further, total immunoglobulin levels increased throughout the experiment in both groups of fish. This observation could be related to seasonal rhanges in the production of immunoglobulins as has been reported by Yamaguchi et al. (1980). It is of importance to note that the increase in total immunoglobulin correlated with a general increase in the OD values in the ELISA measuring antibodies specific to different larval stages of $D$. spathaceum in plasma. This increase is probably caused by non-specific interactions between fish antibodies and parasite antigens.

In mammals, induction of cellular immunity is required to give protection to helminth infections. In schistosomiasis, for example, damage of the schistosomula is mainly caused by antibody and/or complement-dependent adherence of eosinophilic granulocytes (eosinophils), although macrophages and neutrophils also take part in damaging and killing the parasites (for reviews see McLaren 1980, Joseph 1982, Butterworth 1984). Similarly, complement-mediated leucocyte adherence resulting in damage to plerocercoid larva of the cestode Ligula intestinalis have been demonstrated in roach Rutilus rutilus (Hoole \& Arme 1986). Eosinophilic granulocytes have been reported to occur in rainbow trout (Ellis 1977, Bielek 1981). No eosinophils were, however, observed in the blood smears from fish in the present study. Instead, infected fish showed a marked increase in the proportions of neutrophils and monocytes. These findings are related to observations from histological sections of infected fish, in which neutrophils and moncytes/macrophages were found to be associated with the migrating diplostomulae (Erasmus 1959, Ratanarat-Brockelman 1974). It remains to be seen whether or not these cells take part in a cytotoxic reaction against Diplostonum spatheceum.

In conclusion, Diplostonum spathaceum evoked a humoral antibody response in fish injected with parasite antigens but specific antibodies were not detected when fish were infected by the natural route. The recovery of the parasite, however, decreased throughout the experimental period, which indicates that an induction of protective immunity occurred. This protection could be related to the increased proportions of neutrophils and monocytes in the infected fish.
Acknowledgements. We thank Dr G. Houghton and Dr C. Fossum for their valuable criticism on the paper and Dr S. K. Whyte for providing us with parasite eggs. This work was supported by grants from the Swedish Council for Forestry and Agricultural Research and the Royal Swedish Academy of Science.

\section{LITERATURE CITED}

Bielek, B. (1981). Development stages and localization of peroxidatic activity in the leucocytes of three teleost species (Cyprinus carpio L.; Tinca tinca L.; Salmo gairdneri Richardson). Cell Tissue Res. 220: 163-180

Bortz, B. M., Kenny, G. E., Pauley, G. B., Bunt-Milham, A. H (1988). Prevalence of two site-specific populations of Diplostomum spn. in eye infertions of rainbow trout, Salmo gairdneri Richardson, from lakes in Washington State, USA. J. Fish Biol. 33: 31-43

Bortz, B. M. Kenny, G. E., Pauley, G. B., Garzia-Ortigoza, E., Anderson, P. P. (1984). The immune response in immunized and naturally infected rainbow trout (Salmo gairdneri) to Displostomum spathaceum as detected by enzyme-linked immunosorbent assay (ELISA). Devl comp. Immun., N. Y 8: 813-822

Butterworth, A. E. (1984). Cell-mediated damage to helminths. In: Baker, J. R., Müller, R. (eds.) Advanced Parasitology, Vol. 23, London, Academic Press, p. 143-207

Cottrell, B. (1977). The immune response of plaice (Pleuronectes platessa L.) to the metacercariae of Cryptocotyle lingua and Rhipidocotyle johnstonei. Parasitology 74: 193-197

Ellis, A. E. (1977). The leucocytes of fish: a review. J. Fish Biol 11: $453-491$

Erasmus, D. A. (1959). The migration of Cercariae $X$ Baylis (Strigeida) within the fish intermediate host. Parasitology 49: $173-190$

Harris, J. E. (1970). Precipitin production by chub (Leuciscus cephalus) to an intestinal helminth. J. Parasit. 56: 1035

Harris, J. E. (1972). The immune response of a cyprinid fish to infections of the achanthocephalan Pomphorhyncus laevis. Int. J. Parasitol. 2: 459-469

Harris, J. E., Cottrell, B. J. (1976). Precipitating activity in the sera of plaice, Pleuronectes platessa L. to a helminth antigen. J. Fish Biol. 31: 405-410

Hoole, D. Arme, C. (1986). The role of serum in leucocyte adherence to the plerocercoid of Ligula intestinalis (Cestoda: Psuedophyllidea). Parasitology 92: 413-424

Ingram, G. A., Al-Yaman, F. (1988). A comparative assessment of four serological methods used in the detection and measurement of anti-parasite antibodies in the serum of the amphibian, Bufo viridis. Int. J. Parasitol. 18: 371-377

Joseph, M. (1982). Effector functions of phagocytic cells against helminths. Clinics in Immunology and Allergy 2 : $567-596$

Kennedy, C. R., Walker, P. J. (1969). Evidence for an immune response by dace, Leuciscus leuciscus, to infection by the cestode Caryophyllaeus laticeps. J. Parasitol. 55: 579-582

McArthur, C. P. (1978). Humoral antibody production by New Zealand eels, against the intestinal trematode Telogaster opisthorchis Macfarlane, 1945. J. Fish Dis. 1: 377-387

McLaren, D. J. (1980). Schistosoma mansoni: the parasite surface in relation to host immunity. New York: Wiley, p. 229

McVicar, A. H., Fletcher, T C. (1970). Serum factors in Raja radiata toxic to Acanthobothrium quadripartitum (Cestoda: Tetraphyllidae), a parasite specific to $R$. naevus. Parasitology 61.55-63 
Molnar, K., Berczi I. (1965). Nachweis von parasitenspezifischen Antikörpern in Fischblut mittels der Agar-GelPräzipitationsprobe. Z. Inmun. Allergieforsch. 129 263-267

Orr, T S. C., Hopkins, C. A., Charles, G. H. (1969). Host specificity and rejection of Schistocephalus solidus. Parasitology 59: 683-690

Ratanarat-Brockelman. C. (1974). Migration of Diplostomum spathaceum (Trematoda) - in the fish intermediate host. Z. ParasitKde 43: 123-134

Shariff, M., Richards, R. H., Sommerville, C. (1980). The histopathology of acute and chronic infections of rainbow trout, Salmo gairdneri Richardson, with eye flukes Diplostomum spp. J. Fish Dis. 3: 455-465

Speed, P., Pauley, G. B. (1985). Feasability of protecting rainbow trout, Salmo gairdneri Richardson, by immunizing against the eye fluke, Diplostomum spathaceum. J. Fish Biol. 26: 739-744

Stables, J. N., Chappell, L. H. (1986a). Putative immune response of rainbow trout Salmo gairdneri to Diplostomum spathaceum infections. J. Fish Biol. 29: 115-122

Stables, J. N., Chappell, L. H. (1986b). The epidemiology of diplostomiasis in farmed rainbow trout from north-east Scotland. Parasitology 93: 699-710

Szalai, A. J., Danell, G. V., Dick, T A. (1988). Intestinal leakage and precipitating antibodies in the serum of quill-

Responsible Subject Editor: Professor W. Körting, Hannover, F. R. Germany back, Carpiodes cyprinus (Lesueur), infected with Neoechinorhynchus carpiodi Dechtiar, 1968 (Achanthocephala: Neoechinorhynchidae). J. Parasitol. 74: $415-420$

Thuvander, A., Norrgren, L., Fossum, C. (1987). Phagocytic cells in blood from rainbow trout (Salmo gairdneri Richardson) characterized by flow cytometry and electron microscopy. J. Fish Biol. 31. 197-208

Whyte, S. K., Allan, C. J., Secombes, C. J., Chappell, L. H. (1987). Cercariae and diplostomules of Diplostomum spathaceum (Digenea) elicit an immune response in rainbow trout, Salmo gairdneri, Richardson. J. Fish Biol. 31 (Suppl. A): 185-190

Whyte, S. K., Chappell, L. H., Secombes, C. J. (1988). In vitro transformation of Diplostomum spathaceum (Digenea) cercariae and short term maintenance of post-penetration larvae in vitro. J. Helminth. 62: 293-302

Wood, B. P., Matthews, R. A. (1987). The immune response of the thick-lipped grey mullet, Chelon labrosus (Risso, 1826), to metacercarial infections of Cryptocotyle lingua (Creplin, 1825). J. Fish Biol. 31 (Suppl. A): 175-183

Yamaguchi, N., Teshima, C., Kurashige, S., Saito, T., Mitsuuhashi, S. (1980). Seasonal modulation antibody formation in rainbow trout (Salmo gairdneri). In: Solomon, J. B. (ed.) Aspects of developmental and comparative immunology Pergamon Press, Oxford, p. 483-484

Manuscript first received: September 18, 1989

Revised version accepted: January 16, 1990 